\title{
Analysis of Rainfall Variability on the Groundwater Levels of Wells in the Nouaho Basin in East-Central Burkina Faso
}

\author{
Lucien Damiba1,2, Ali Doumounia1,3, Vincent Casey², Alice Bounkoungou², François Zougmoré1 \\ ${ }^{1}$ Materials and Environment Laboratory (LA.M.E.), Department of Physics, University Joseph KI-ZERBO, Ouagadougou, \\ Burkina Faso \\ ${ }^{2}$ WaterAid, International Program Department, West Africa Research and Knowledge Management, Ouagadougou, Burkina Faso \\ ${ }^{3}$ Institute of Science (IDS), Ouagadougou, Burkina Faso \\ Email: ali.doumounia@ids-ouaga.bf
}

How to cite this paper: Damiba, L., Doumounia, A., Casey, V., Bounkoungou, A. and Zougmoré, F. (2020) Analysis of Rainfall Variability on the Groundwater Levels of Wells in the Nouaho Basin in East-Central Burkina Faso. Journal of Water Resource and Protection, 12, 964-974. https://doi.org/10.4236/jwarp.2020.1211057

Received: September 18, 2020

Accepted: November 27, 2020

Published: November 30, 2020

Copyright $\odot 2020$ by author(s) and Scientific Research Publishing Inc. This work is licensed under the Creative Commons Attribution International License (CC BY 4.0).

http://creativecommons.org/licenses/by/4.0/

\section{(c) (i) Open Access}

\begin{abstract}
Sahelian countries are confronted with a lack of reliable data on water and climate allowing them to understand the effects of climate variability. To address this situation, with the support of Water Aid, we have collected rainfall data and groundwater level in wells from 2012 to 2018 with help of local populations. Their contribution made it possible to cover a wider geographical area and to obtain the data necessary to analyze the climate variability on a small and large scale in the sub-basin of the Nouhao. The data collected are well correlated with those collected from the rain gauges of the national meteorological agency in the region of Fada N'Gourma. From 2012 to 2018, August appears to be the rainiest month. It recorded, alone, $1 / 3$ of the average annual rainfall. The depletion of surface water tables is faster after the rainy season. The static level of the water table in the crystalline subsoil also depletes and replenishes at night after the peak water collection time, which is between noon and 8 p.m. These few years of measuring rainfall and groundwater fluctuations have shown that the correlation between rainfall and groundwater level is clearly established. Nevertheless this needs to be more investigated during a longer period to confirm the robustness of the method. On the other hand, the approach to securing water resources based on community monitoring of water resources gives good results in accordance with the National Meteorological Agency and the Directorate of water resources, however, caution recommends continuing measurements over a few decades to confirm its robustness for this aspect too.
\end{abstract}

\section{Keywords}

Groundwater, Climate Variability, Nouhao, Rainfall 


\section{Introduction}

West African countries and notably those in the Sahel have experienced an unusual climate change since the 70 's. This was the result of, on the one hand, the high increase of average temperature in a year and on the other hand, the significant rainfall [1] [2] [3] [4]. This leads to long droughts or floods which makes communities vulnerable to climate change [5] [6] [7] [8]. The increased vulnerability and fragility of environment have to do with climate change as well as with communities' poor socio-economic conditions [9]. In Burkina Faso, the human-based activities focus on farming and livestock breeding, and tree felling coupled with low rainfall in an area which is ecologically fragile, are sources of rapid degradation of environment. A significant trend of migration of isohyets from north to south, rainfall variability and temperature increase characterize the manifestations of climate change in Burkina Faso with the consequences on water resources which are accentuated year by year [10] [11]. In Burkina Faso, where $80 \%$ of the population depends, for the $2 / 3$ of the year, on water from boreholes and wells, groundwater in particular is of strategic importance for human development and for the balance of the environment. Thus, several authors [12] [13] mentioned that rainfall variability and the variation of the underground level are intimately linked. However, more investigation is required to take into account the climate change experienced in the region during the 1970s. This study aims to understand the manifestations of rainfall variability and its effects on groundwater in the Nouhao basin.

\section{Data and Methods}

\subsection{Study Area}

Figure 1 shows the study area. The basin is located in the East Central Region of Burkina Faso. The materials used are water whistles, electric dip meters and level loggers to monitor the groundwater level and simple raingauges to measure the rainfall. The data have been collected by community volunteers through the Water security project led by WaterAid with the support of the National Meteorological Service. The data consist of a series of rainfall and groundwater data collected from 2012 to 2018 in three communities-Sablogo, Basbedo and Loungo-in the study area. Within the basin, the National Piezometric Network has only three piezometers situated in Bittou, Bousgou and Sela. In addition, there are huge gaps in the series of data. This is the reason why we chose to initiate this method using wells and boreholes, equipped with the material listed above, in the basin for the study.

\subsection{Groundwater Level Measurement}

To monitor the variations in the water level, the Static Level (SL) was the parameter that was measured every morning at the first hour before any abstraction, according to the national piezometer measurement protocol [14]. In view of the insufficient means to install enough piezometers and monitor them, we followed 


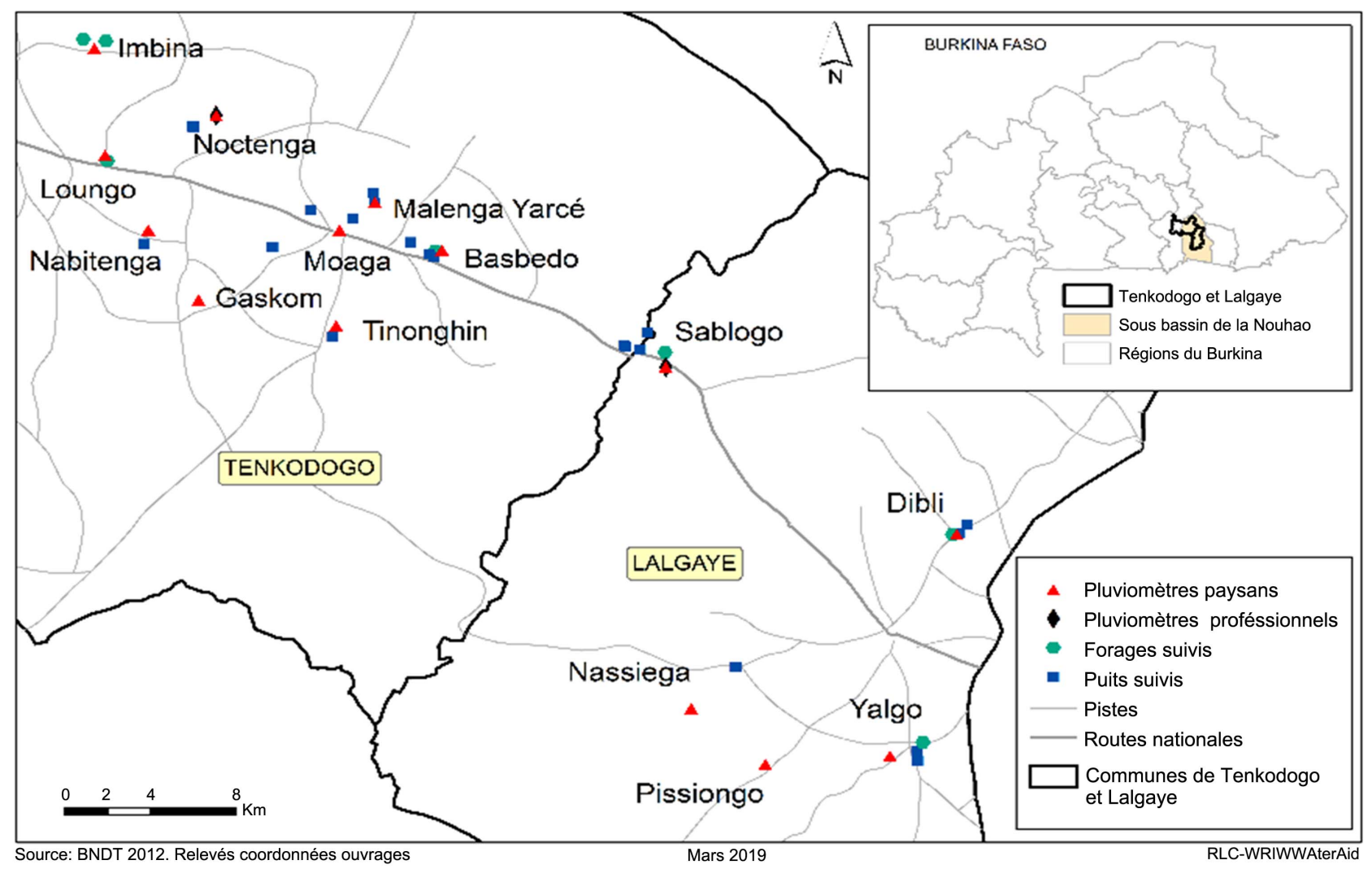

Figure 1. Location of monitoring wells and rainfall stations in the study area.

up on the "dynamic" wells and subsequently made adjustments to comply with the hydrogeological norms [15]. In fact, the whole basin has only three piezometers (Bittou, Bousgou and Sela) installed by the General Directorate of Water Resources. The choice to monitor operating wells, offers the opportunity to obtain data allowing having knowledge of the dynamics of the water resources. The data collected are then recorded in the recording sheets kept by the reader who gives copies to the Technical Unit of the project composed of the state agencies (Environment, water and sanitation, livestock, agriculture), the technical services of the targeted municipalities and the WaterAid Water Resources Center. The data used are collected at weekly basis from hand dug wells by community monitor. Data from boreholes have been recorded by a data logger at an hourly basis.

\subsection{Rainfall Data}

The data used are daily rainfall collected by community monitors recruited and trained by the WaterAid with the support of Burkina Faso's National Meteorological Agency (ANAM). They consist of a series of data collected from 2012 to 2018 in three villages in the Nouaho basin. Data are collected using a peasant raingauge of the SPIEA type manufactured by SIMPLAST SA in Mali and distributed by Mali Meteo in the ECOWAS zone. This study covers the community of Basbedo, Loungo located in the department of Tenkodogo and Sablogo-department of Lalgaye in the central-eastern region of Burkina Faso. This re- 
gion is in the Sudanese climatic zone where annual rainfall ranges between 700 and $900 \mathrm{~mm}$. The subbasin straddles the North Sudanese climatic zone and the Sudanese zone with annual rainfall of 700 to $800 \mathrm{~mm}$ and $800 \mathrm{~mm}$ and above [16].

\subsection{Validation Data}

We have applied the following two control levels to validate the data:

Primary control: This involves checking the compliance of data collected by the community volunteers using the monitoring protocol. For underground water, the focus was to measure time and the static level compared to the base level. Another check was the quality of data logging to understand what we observed. A similar control was done for rainfall to assess the amount of rain per day, the rain days, the total rain per week and month. This control process falls under the responsibility of the project monitoring Officer of the relevant NGO.

Quality control: comparing the data recorded by community volunteers with panel data that are recorded using the appropriate resources or tools. For the underground water, loggers are installed in the wells to be monitored. These loggers are set up with values per hour to record fluctuation of well water for 6 months to 1 year. Then data are compared to those collected by the community volunteer.

On rainfall, ANAM supported the installation of two professional rain gauges near each local rain gauge. In general, measures are recorded in the rainy season (May to October) and we compare the data of both sources.

\section{Results}

The Loungo, Basbedo and Sablogo communities spread from the West to the East on about $16 \mathrm{~km}$. For the rainfall and groundwater level, we have assessed from December 2011 to December 2018, including rain season period which spans from mid-May to late October. For groundwater fluctuation in the borehole, we faced some challenges in the site of Loungo and Sablogo. The level loggers have been lost and we were not able to have enough data to complete the analysis. We will, therefore, continue with data of Basbedo which are complete.

\subsection{Comparing Rainfall of the Study Area with the Base Station in Fada N'Gourma: Data Validation}

Using the Shapiro-Wilk test [17], the normality stats test for Fada station (W = $0.8378, \mathrm{p}$-value $=0.02602)$ on the average rainfall from 2012 to $2018(\mathrm{~W}=$ 0.8124 and $\mathrm{P}$-value $=0.01302)$ in the study area and the one for last 30 years shows a normal variable in both cases (Figure 2). This situation shows that data collected by communities have similar normality with Fada N'Gourma station. This testifies the quality of data collected even though the period for collection is about 7 years. 


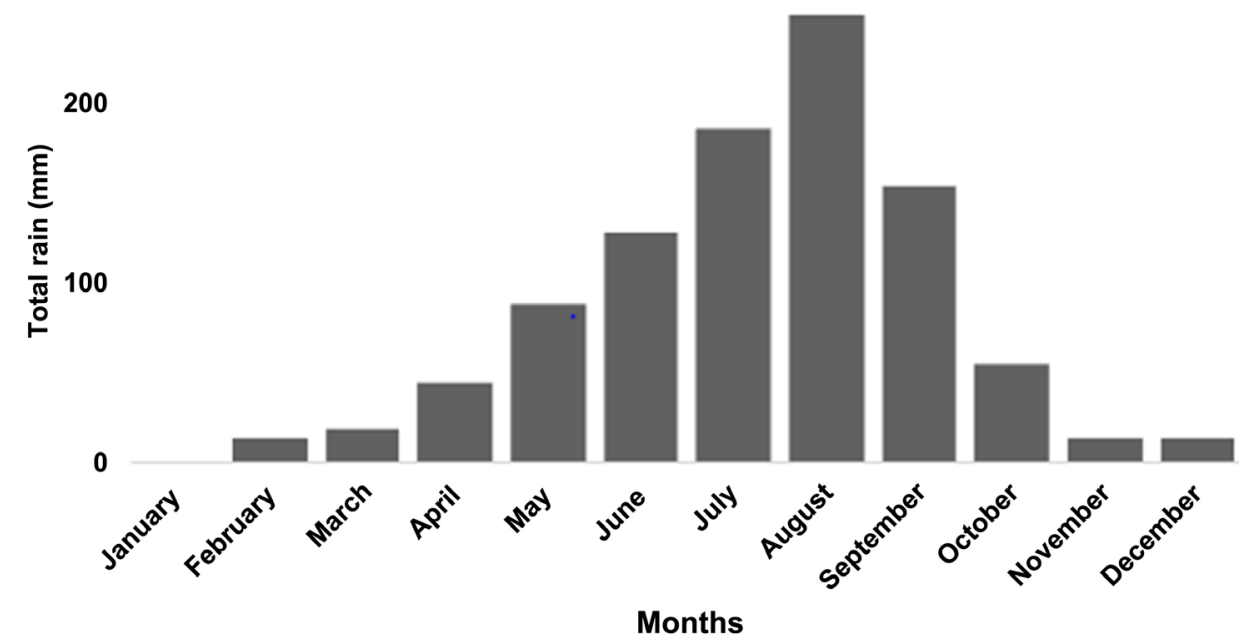

(a)

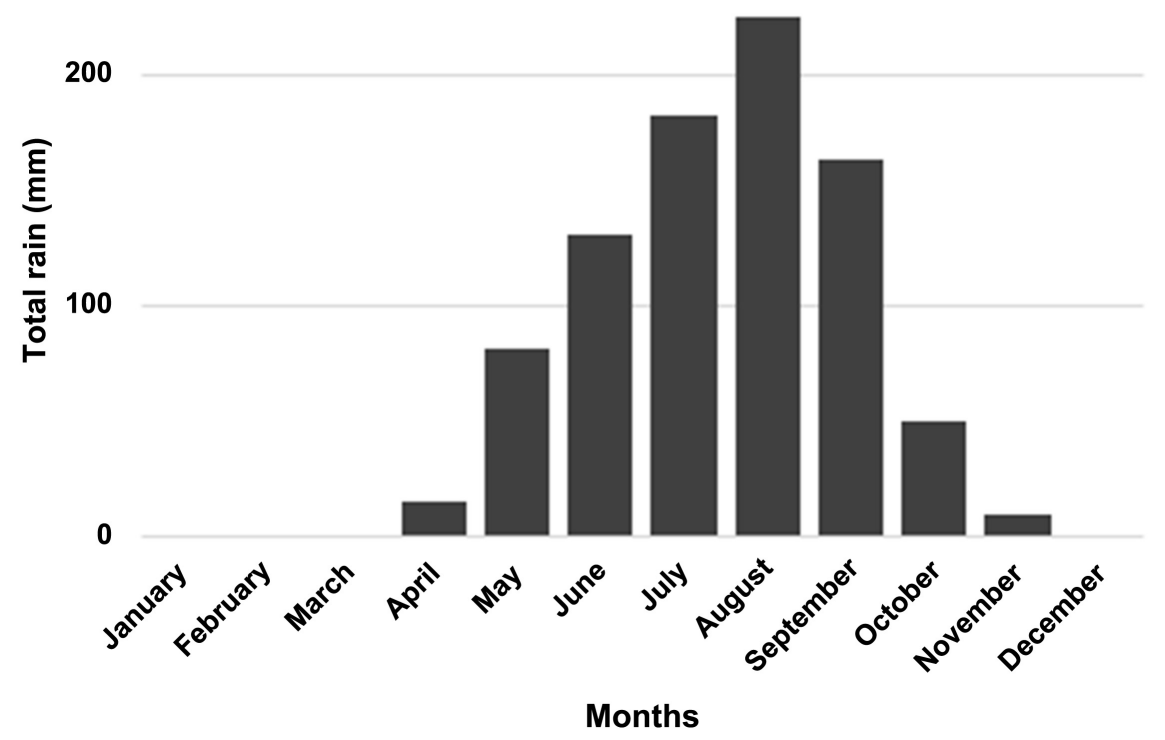

(b)

Figure 2. (a) Rainfall distribution in Fada (1987-2017); (b) Distribution of average rain in the study area from 2012 to 2018 .

\subsection{Rainfall Level in the Study Area}

Rainfall variability is visible, as presented in Table 1: Basbedo station received about $8 \%$ more rain than Loungo and 28\% more than Basbedo during the 7-year period. In terms of percentage of total precipitation in August, Loungo represents the highest amount of precipitation than the others. This represents approximately $32 \%$ of the total amount of precipitation. The average percentage of (non) zero rainy days is $43 \mathrm{~mm}, 49 \mathrm{~mm}$ and $39 \mathrm{~mm}$ respectively in Loungo, Basbedo and Sablogo while the number of days on which all stations receive rain is 11 days. These different figures in the table show the sensitivity of precipitation in the study area due to the natural variability of rainfall in the Sahel caused by the African monsoon [18]. In a conclusion, the rainfall is spatially variable over quite short distances, as is well known in the tropics and elsewhere. 
Table 1. Summary of rainfall data in Loungo, Basbédo and Sablogo from 2012 to 2018.

\begin{tabular}{cccc}
\hline Variables & Loungo & Basbedo & Sablogo \\
\hline Average rainfall from May to October & 784 & 850 & 609 \\
Percentage average rainfall in July & $20 \%$ & $24 \%$ & $23 \%$ \\
Percentage of average rainfall in August & $32 \%$ & $27 \%$ & $26 \%$ \\
Percentage of average rainfall in September & $19 \%$ & $20 \%$ & $20 \%$ \\
Number of average rain days (not zero) & 43 & 49 & 39 \\
Number of days with less than 5 mm & 28 & 37 & 35 \\
\hline
\end{tabular}

\subsection{Water Level Fluctuation in Wells and Boreholes}

The water level varies depending on rainy or dry season. During the dry season, the water level is depleting according to natural discharge and abstraction. In the rainy season, the water level increase depending on the amount of rain, its intensity, the geological nature of the water table and its depth [19]. The more rain in water table with a sandy soil is, the better the infiltration will be. The reaction time of the water table depends on these different factors. Figure 3 below shows that the two wells in Basbedo Community rapidly react when the rain started in May and reach the top level during July and August then start decreasing after the rain stop in September to October. Well water levels respond quickly to local rainfall-recharge, and, probably, to indirect recharge from river flows and flooding of the valleys [18]. In summary, water levels in all wells show a steady decline in the dry season, followed by a rapid response to rainfall and perhaps local runoff in the wet season. At Basbedo the response is even earlier in May, after no rainfall has been recorded in that village. This suggests that indirect, recharge may be contributing to the rise in water levels. After peak water levels are reached, the initial fall is steep from early October at Basbedo. This may be attributable to aquifer permeability in the sites. Figure 4 shows the borehole logger results in Basbedo. It shows the full dry season's record, October 2011-May 2012, while Figure 5 shows the water levels for one week (17-23 April 2012) at the height of the dry season. Over the dry season, water levels in the boreholes follows shallow downward gradients, with water levels stabilizing in June and starting to rise by the beginning of July. Water levels reach their highest in October or November, before starting to fall again during the dry season. The short period records for the boreholes show drawdowns due to daily abstraction of 1.5 - 2 meters, implying transmissivity values in the order of $3 \mathrm{~m}^{2} / \mathrm{d}^{3}$. (Using a pumping rate of $5 \mathrm{~m}^{3} / \mathrm{d}$ in the steady-state Logan equation). Figure 6 shows an hourly record for Basbedo for one day in April 2012, clearly showing the periods of heavy pumping from $03 \mathrm{~h} 30$ to $08 \mathrm{~h} 00$ and again from $10 \mathrm{~h} 30$ to $12 \mathrm{~h} 30$ ), and the recovery of water levels after about 20h30. Diurnal variation in water level in the boreholes is caused by morning peak pumping (from about 03h30) and steady usage through the day, with cessation of pumping and recovery taking place after about $20 \mathrm{~h} 30$. 


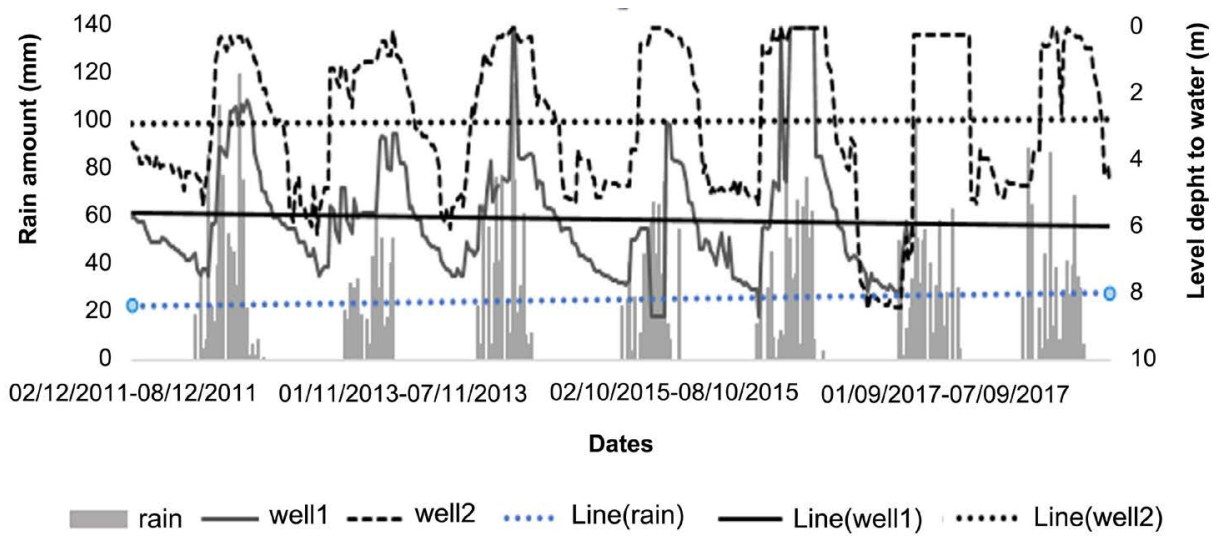

Figure 3. Rainfall status and fluctuation of water table in wells 1 \& 2 in Basbédo.

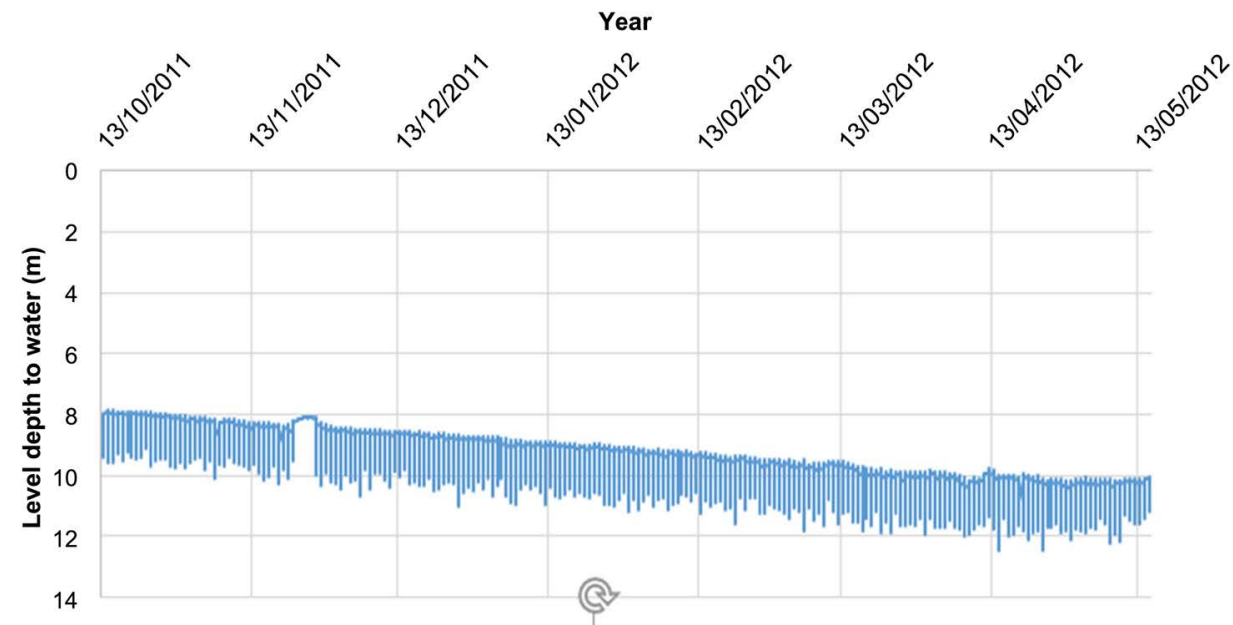

Figure 4. Dry season's (Octobre 2011-May 2012) water fluctuation.

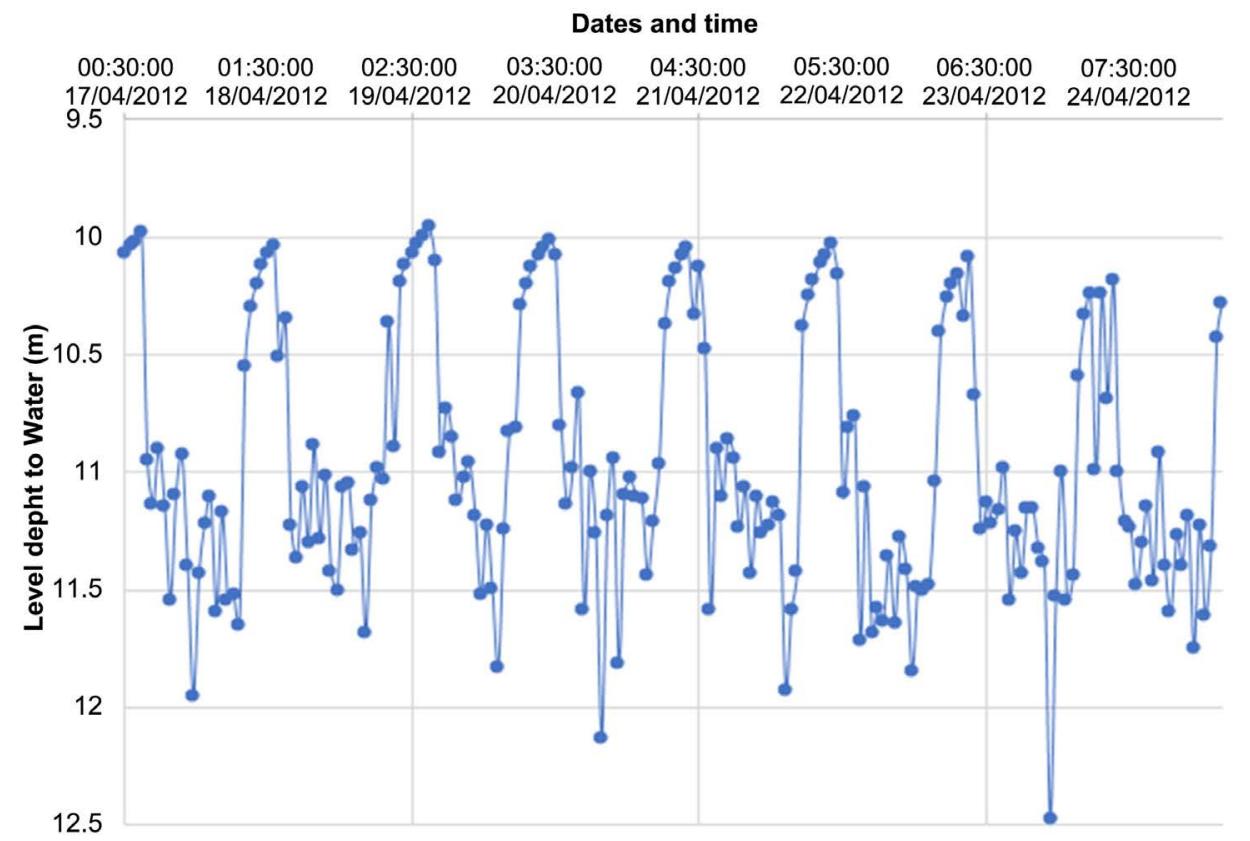

Figure 5. Weekly water level in Basbedo borehole. 


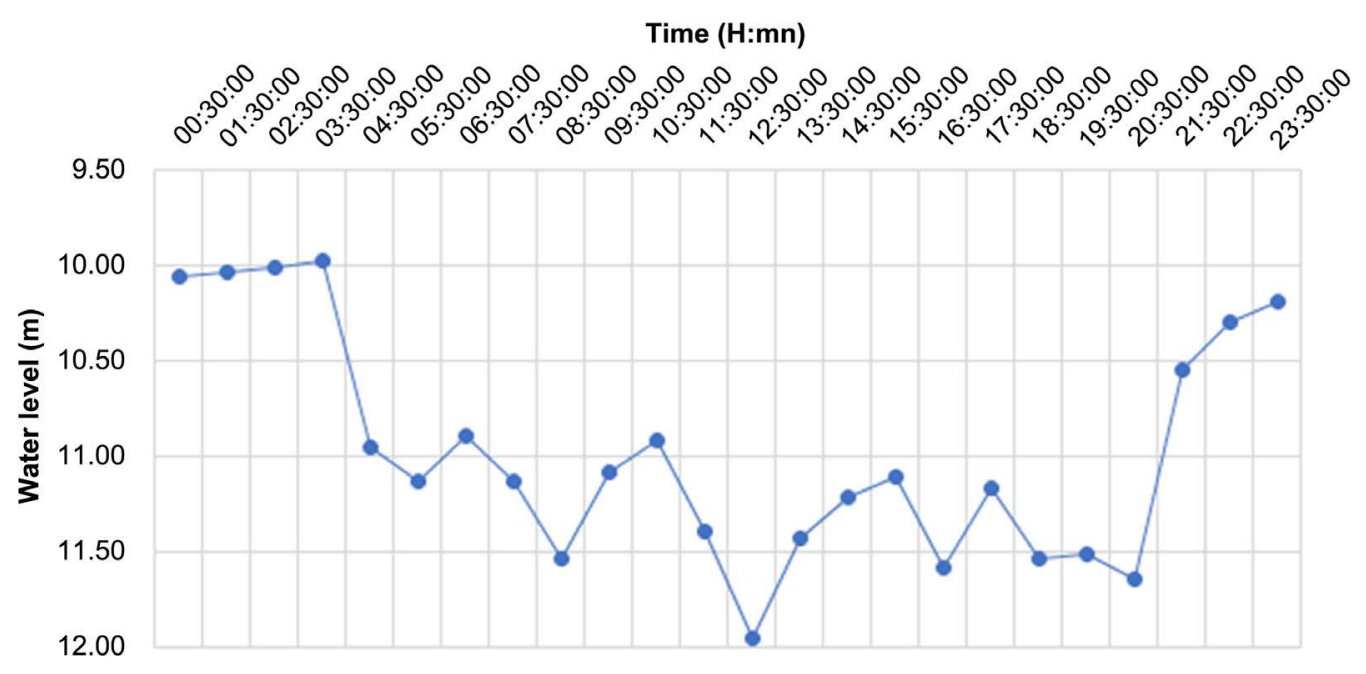

Figure 6. Hourly record for Basbedo for one day (April 2012).

\section{Discussions}

Rainfall in all three stations indicates a spatial variation on about $17 \mathrm{~km}$. This variation is seen in the average rainfall as well as in the number of rain days, but also the number of days when all three stations receive rain at the same time. Observations of the stations show that the rainy season spreads from Mid-April to October. From 2012 to 2018, August records most rain in the year and is followed by July. This situation is similar to all stations of the climate zone. In Fada N'Gourma station, the Shapiro-Wilk normality test carried through [17] on the annual rainfall from 2012 to 2018 in the study area and over the past three years indicates a normal "rain" in both cases. The normality tests on rainfall in the Fada N'Gourma reference station and the one in the study area give similar results. These results describe a Sahel zone earmarked by a normal distribution of rain with a $\mathrm{W}$ value close to measure unit and P-value below 5\%. The Shapiro-Wilk normality test for the Fada N'gourma station shows this $\mathrm{W}=0.8378$ and $\mathrm{p}$-value $=0.02602$. For the reference zone, the result is as follows: Shapiro-Wilk test indicates a figure close to 1 with a P-value far below $5 \%$. So $\mathrm{W}=$ 0.8124 and P-value $=0.01302$. With these test results, one can conclude that the data collected by communities are statistically important and valid for scientific use. The water table fluctuation matches the "dry-raining season" cycle whereby the table depletes during the dry season and replenishes in the rainy period after the first rains or following local water runoff. Depletion is due to either the withdrawal of water for domestic use and/or natural discharge as a result of ground water runoff. Basbedo total population is 951 inhabitants [20], and Pumping total time is 17 hours. Using the national normal for manual hand pump production in rural area which is $0.7 \mathrm{l} / \mathrm{h}$ [21], the total amount of water abstracted during the 17 hours of Pumping time is about $\mathrm{Wa}=\mathrm{Qmax} \times \mathrm{T} ; \mathrm{Wa}=$ $11,900 \mathrm{~L}$. Wa is Water Abstracted, Qmax is the maximal yield of the borehole in manual pumping and $\mathrm{T}$ is the pumping time. Over a period of 8 years of rain, the trend curve indicates an increase of the annual rain $(y=0.0139 x+22.91)$ 
which is similar to the well $1,(y=0.0011 x+5.5609)$ while the trend curve for 2 nd well, is falling $(y=-0.0003 x+2.885)$. This is because both sites are different in terms of replenishing that is related to the soil conditions. The same fluctuation cycle applies to deep water table in a borehole only that, this water table reacts late to the first rains (infiltration takes place). The same reasons account for the seasonal depletion of both surface and ground water tables. The fluctuation in deep water table within a week indicates the gradual but slow depletion by $0.5 \mathrm{~m}$ of the static level in 7 days. The active/dynamic level of water changes depending on the amount withdrawn. Figure 4 shows a recording per hour of fluctuation in Basbedo for one day in April 2012; this clearly shows that the intensive pumping periods are from $03 \mathrm{~h} 30$ to $08 \mathrm{~h} 00$ and from $10 \mathrm{~h} 30$ to $12 \mathrm{~h} 30$. Water level stabilizes after $20 \mathrm{~h} 30$.

\section{Conclusion}

The lack of accurate data on climate and water resources is a major issue in Burkina Faso. In particular, in the Nouaho basin, only three piezometers and two rainfall stations have been installed by the General Directorate of Water Resource and the National Meteorological agency of Burkina Faso. The current study was made possible through networking of committed community monitors; transfer of skills from specialized institutions to community members and the use of simple tools for collecting data. The value of this approach lies in the involvement of communities in the selection of community volunteers/monitors, cooperation between communities and expert institutions, use of tools that are affordable and accessible to communities, local authorities' engagement in data collection, processing and interpretation of collected data. The approach also helps not only to increase the number of measure tools but also allows having quality data over time. The critical mass of data will help the research move forward in order to better understanding the climate change both at small and large scales. The experience in Nouhao Basin in Burkina has helped to know that the graph from the data collected by communities is similar to the one in Fada N'Gourma seen as the reference station met office. The Approach could be easily replicable in other basins across Africa. From a social perspective, the benefit of involving communities is their ownership for building their climate resilience. Results achieved are good both in terms of quality of data but also on knowledge of water resources as well as climate variability. However, a lot depends on community participation and voluntary efforts of data collectors. The approach can be improved to fill the data gap, given that this gap thwarts the socio-economic development of people faced with climate change. This is a promising initiative, which would be more credible if the scientific community is associated with, first of all, work at a wider scale in different contexts and also improves the approach.

\section{Acknowledgements}

We gratefully acknowledge WaterAid, for supporting this research. We also 
gratefully acknowledge the National Meteorological Agency of Burkina Faso for providing the reference rain gauge data.

\section{Conflicts of Interest}

The authors declare that they have no competing interests.

\section{References}

[1] Dai, A., Trenberth, K.E. and Karl, T.R. (1998) Global Variations in Droughts and Wet Spells: 1900-1995. Geophysical Research Letters, 25, 3367-3370. https://doi.org/10.1029/98GL52511

[2] Descroix, L., Niang, A.D., Panthou, G., Bodian, A., Sane, Y., Honoré, D., Abdou, M.M., Vandervaere, J.-P. and Quantin, G. (2015) Évolution récente de la pluviométrie en Afrique de l'ouest à travers deux régions: La Sénégambie et le Bassin du Niger Moyen. Climatologie, 12, 25-43. https://doi.org/10.4267/climatologie.1105

[3] E. Servat et al. (1998) Identification, caracterisation et consequences d'une variabilite hydrologique en Afrique de l'ouest et central. Wafer Resources Variability in Africa during Ihe XXth Cen Jury Proceedings, No. 252.

[4] Kabore, P.N., Ouedraogo, A., Sanon, M., Yaka, P. and Some, L. (2017) Caractérisation de la Variabilité Climatique Dans la Région du Centre-Nord du Burkina Faso Entre 1961 et 2015. Climatologie, 14, 82-95. https://doi.org/10.4267/climatologie.1268

[5] Ardoin-bardin, S., Servat, E. and Dezetter, A. (2003) Analyse de la persistance de la sécheresse en Afrique de l' ouest: Caractérisation de la situation de la décennie 1990. No. January 2015.

[6] Ardoin-Bardin, S. (2004) Variabilité hydroclimatique et impacts sur les ressources en eau de grands bassins hydrographiques en zone soudano-sahélienne. Thèse l'Université Montpellier II Sci. Tech. du Languedoc, Montpellier, Fr., 608.

[7] Cantoni, C. and Lallau, B. (2016) The Resilience of Turkanas. A Community of Kenyan Herdsmen Experiencing Climatic and Political Uncertainties. Développement Durable et Territoires, 1, 23.

[8] Ali, D., Aminata, Z., Lucien, D., François, Z. and Michel, N. (2020) Analyse de la variabilite climatique dans le sous bassin de nouhao au centre-est du burkina faso [Climate Variability Analysis in the Nouhao Sub-Basin in Eastern Center of Burkina Faso]. LARHYSS Journal, 41, 57-69.

[9] Diello, P., Mahe, G., Paturel, J.-E., Dezetter, A., et al. (2005) Relations indices de végétation-pluie au Burkina Faso: Cas du bassin versant du Nakambé [Relationship between Rainfall and Vegetation Indexes in Burkina Faso: A Case Study of the $\mathrm{Na}-$ kambe Basin]. Journal des Sciences Hydrologiques, 50, 207-221.

[10] Massuel, S. (2005) Evolution récente de la ressource en eau consécutive aux changements climatiques et environnementaux du sud-ouest Niger. Modélisation des eaux de surface et souter-raines du bassin du kori de Dantiandou sur la période 1992-2003. Université Montpellier II, Montpellier.

[11] Ibrahim, B. (2012) Caractérisation des saisons de pluies au Burkina Faso dans un contexte de changement climatique et évaluation des impacts hydrologiques sur le bassin du Nakambé. Université Pierre et Marie Curie et de l'Institut International d'Ingénierie de l'Eau et de l'Environnement (2ie).

[12] Mahé, G., Olivry, J.-C., Dessouassi, R., Orange, D., Bamba, F. and Servat, E. (2000) Relations eaux de surface-eaux souterraines d'une riviere tropicale au Mali. Comptes 
Rendus I Academie Sci.-Ser. IIa Sci. la Terre des Planetes, 330, 689-692. https://doi.org/10.1016/S1251-8050(00)00188-9

[13] Ouandaogo-Yameogo, S., Blavoux, B., Nikiema, J. and Savadogo, A.N. (2013) Caractérisation $\mathrm{du}$ fonctionnement des aquifères de socle dans la région de ouagadougou à partir d'une étude de la qualité chimique des eaux. Revue des sciences de l'eau, 26, 173-191. https://doi.org/10.7202/1018784ar

[14] Koussoube, Y. (1996) Hydrogéologie en milieu de socle cristallin du Burkina Faso: cas du bassin versant du bas-fond de Bidi (province du Yatenga). Université Cheikh Anta Diop de Dakar.

[15] WaterAid (2016) Improving Water Security and Management of Water Resources in Sahelian WASH Programmes: A Toolkit.

[16] Damiba, L., Doumounia, A., Zeba, A., Traoré, T.N., Sawadogo, C.O. and Zougmoré, F. (2020) Forecast Analysis of Hydro-climatic Data of Nouhao Sub-Basin in East-Central of Burkina Faso. International Journal of Environmental Monitoring and Analysis, 8, 27-32. https://doi.org/10.11648/j.ijema.20200802.12

[17] Shapiro, S.S. and Wilk, M.B. (1965) An Analysis of Variance Test for Normality (Complete Samp1es). Biometrika, 52, 591-611.

https://doi.org/10.1093/biomet/52.3-4.591

[18] WaterAid (2013) Strengthening WASH Services and Community Resilience through Community-Based Water Resource Management. Ouagadougou.

[19] Filippi, C., et al. (2014) Evaluation de la recharge naturelle des aquifères en climat soudano sahélien par modélisation hydrologique globale: Application à dix sites au Burkina Faso. HAL ID: hal-01061972.

[20] Sougrinoma, S.H.A. (2012) Mise en place d' une gestion communautaire des risques de désastres liés aux changements climatiques dans trois villages de la région $\mathrm{du}$ Centre-Est du Burkina. Université de ouagadougou.

[21] Ouédraogo, M. (2012) Impact des changements climatiques sur les revenus agricoles au Burkina Faso. Journal of Agriculture and Environment for International Development, 106, 3-21. 